Pacific Northwest

National Laboratory

Operated by Battelle for the

U.S. Department of Energy

\title{
Application of Diagnostic/Prognostic Methods to Critical Equipment for the Spent Nuclear Fuel Cleanup Program
}

\author{
L. O. Casazza \\ R.J. Meador \\ D. B. Jarrell \\ D.E. Wallace
}

T. M. Koehler

February 2002

Prepared for the U.S. Department of Energy

under Contract DE-AC06-76RL01830 


\title{
DISCLAIMER
}

This report was prepared as an account of work sponsored by an agency of the United States Government. Neither the United States Government nor any agency thereof, nor Battelle Memorial Institute, nor any of their employees, makes any warranty, express or implied, or assumes any legal liability or responsibility for the accuracy, completeness, or usefulness of any information, apparatus, product, or process disclosed, or represents that its use would not infringe privately owned rights. Reference herein to any specific commercial product, process, or service by trade name, trademark, manufacturer, or otherwise does not necessarily constitute or imply its endorsement, recommendation, or favoring by the United States Government or any agency thereof, or Battelle Memorial Institute. The views and opinions of authors expressed herein do not necessarily state or reflect those of the United States Government or any agency thereof.

\section{PACIFIC NORTHWEST NATIONAL LABORATORY \\ operated by \\ BATTELLE \\ for the \\ UNITED STATES DEPARTMENT OF ENERGY}

under Contract DE-AC06-76RL01830

Printed in the United States of America

Available to DOE and DOE contractors from the

Office of Scientific and Technical Information,

P.O. Box 62, Oak Ridge, TN 37831-0062;

ph: (865) 576-8401

fax: (865) 576-5728

email: reports@adonis.osti.gov

\author{
Available to the public from the National Technical Information Service, \\ U.S. Department of Commerce, 5285 Port Royal Rd., Springfield, VA 22161 \\ ph: (800) 553-6847 \\ fax: (703) 605-6900 \\ email: orders@ntis.fedworld.gov \\ online ordering: http://www.ntis.gov/ordering.htm
}

This document was printed on recycled paper.

$(8 / 00)$ 
PNNL-13796

\section{Application of Diagnostic/ Prognostic Methods to Critical Equipment for the Spent Nuclear Fuel Cleanup Program}

Prepared by: Larry O. Casazza, Don B. Jarrell, Theresa M. Koehler, Richard J. Meador, Dale E. Wallace

Pacific Northwest National Laboratory

February 2002 


\section{SUMMARY}

The management of the Spent Nuclear Fuel (SNF) project at the Hanford K-Basin in the $100 \mathrm{~N}$ Area has successfully restructured the preventive maintenance, spare parts inventory requirements, and the operator rounds data requirements. In this investigation, they continue to examine the different facets of the operations and maintenance (O\&M) of the K-Basin cleanup project in search of additional reliability and cost savings.

This preliminary report focuses on the initial findings of a team of PNNL engineers engaged to identify potential opportunities for reducing the cost of O\&M through the application of advanced diagnostics (fault determination) and prognostics (residual life/reliability determination). The objective is to introduce predictive technologies to eliminate or reduce high impact equipment failures.

The PNNL team in conjunction with the SNF engineers found the following major opportunities for cost reduction and/or enhancing reliability:

1. Provide data routing and automated analysis from existing detection systems to a display center that will engage the operations and engineering team. This display will be operator intuitive with system alarms and integrated diagnostic capability.

2. Change operating methods to reduce major transients induced in critical equipment. This would reduce stress levels on critical equipment.

3. Install a limited sensor set on failure prone critical equipment to allow degradation or stressor levels to be monitored and alarmed. This would provide operators and engineers with advance guidance and warning of failure events.

Specific methods for implementation of the above improvement opportunities are provided in the recommendations. They include an Integrated Water Treatment System (IWTS) decision support system, introduction of variable frequency drives on certain pump motors, and the addition of limited diagnostic instrumentation on specified critical equipment. 


\section{ACKNOWLEDGEMENT}

The PNNL team would like to acknowledge the invaluable assistance of the engineers and management of the Spent Nuclear Fuel project who contributed time, expertise and ideas toward the successful completion of this report. 


\section{Table of Contents}

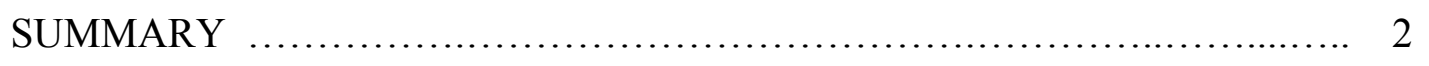

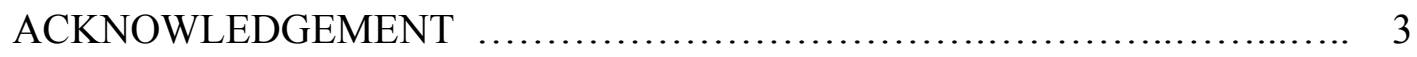

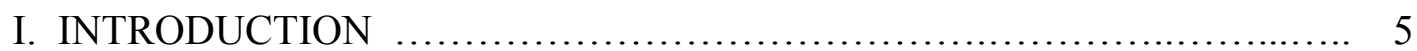

A. SNF Cleanup Mission …..................................... 5

B. SNF Preventive Maintenance Project .............................. 5

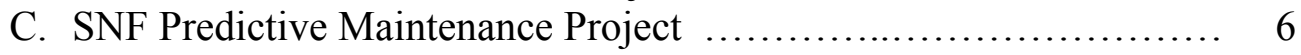

II. PREDICTIVE MAINTENANCE EVALUATION METHODOLOGY ..... 6

III. K-WEST INTEGRATED WATER TREATMENT SYSTEM $\ldots \ldots \ldots \ldots \ldots . . . . .7$

A. IWTS System Analysis ......................................... 8

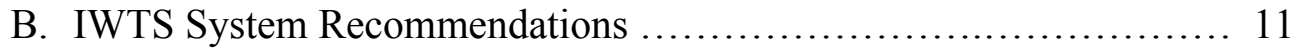

IV. CVD VACUUM PUMPS ............................................. 17

A. CVD Vacuum Pump Analysis .................................. 17

B. CVD Vacuum Pump Recommendation .......................... 18

V. CVD SUPPLY, EXHAUST, AND RECIRCULATION FANS............... 18

A. CVD Supply, Exhaust, and Recirculation Fan Analysis ............... 18

B. CVD Supply, Exhaust, and Recirculation Fan Recommendations ..... 19

VI. CVD UNINTERRUPTIBLE POWER SUPPLY ........................... 19

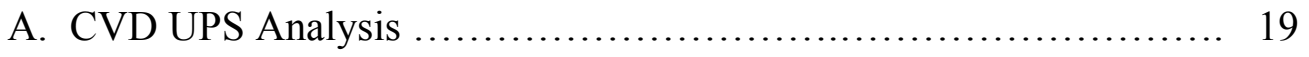

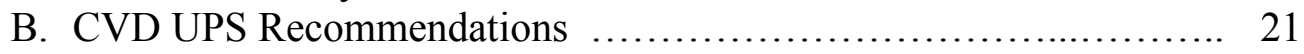

VII. CVD HVAC GENERAL EXHAUST VARIABLE FREQUENCY DRIVE... 21

A. CVD Variable Frequency Drive Analysis ......................... 22

B. CVD Variable Frequency Drive Recommendations .................. 22

\section{APPENDICES}

A. Plots of Various Starting Transients for the IWTS Pumps P1, P2, and P3

B. Plots of CVD Vacuum Pump Suction Pressures 


\section{INTRODUCTION}

The K Basins are located on the south bank of the Columbia River near the north end of the Hanford Site. The K Basins, built in the early 1950s, are two large basins for underwater storage of irradiated fuel produced by the K Reactors. The basins presently store a large quantity of N Reactor spent nuclear fuel (SNF) that has been deteriorating for many years. A small amount of single pass reactor fuel is also stored in the basins.

\section{A. SNF Cleanup Mission}

The U.S. Department of Energy (DOE) established the SNF Project to address safety and environmental issues associated with the deteriorating fuel presently stored underwater in the basins. Recommendations for a series of projects to construct and operate systems and facilities to manage the safe removal of SNF fuel were made in WHC-EP-0830, Hanford Spent Nuclear Fuel Recommended Path Forward, ${ }^{1}$ and its subsequent update, WHC-SD-SNF-SP-005, Hanford Spent Nuclear Fuel Project Integrated Process Strategy for K Basin Fuel. ${ }^{2}$ The integrated process strategy recommendations include:

1. Fuel preparation activities at the basins, and packaging the fuel into MultiCanister Overpacks (MCO).

2. Transportation of MCO loaded with SNF from the basins to the Cold Vacuum Drying Facility (CVDF).

3. Removal of free water from the MCO by draining and vacuum drying at the CVDF in the $100 \mathrm{~K}$ Area.

4. Dry shipment of fuel from the CVDF to the Canister Storage Building (CSB), a new facility in the 200 East Area.

5. Interim storage of the $\mathrm{MCO}$ in the CSB until a suitable long-term repository is established.

\section{B. SNF Preventive Maintenance Project}

In December of 2000, the first MCO was processed from the K West Basin through the CVD and successfully stored in the CSB repository. This marked a transition point for all three facilities, in that they had now completed construction for meeting the SNF goals and had become true processing facilities. Following this milestone, risk-based examinations of the SNF preventive maintenance program and SNF spare parts program were performed by a PNNL team and summarized in SNF-8346, Cost-Effective Maintenance Structure for the Spent Nuclear Fuel Cleanup Program ${ }^{3}$ and SNF-9290, Prioritization of Spare Parts for the Spent Nuclear Fuel Cleanup Program 4 .

${ }^{1}$ WHC-EP-0830, 1994, Hanford Spent Nuclear Fuel Recommended Path Forward, Rev. 0, Westinghouse Hanford Company, Richland, Washington.

2 WHC-SD-SNF-SP-005, 1995, Hanford Spent Nuclear Fuel Project Integrated Process Strategy for SNFs Fuel, Rev. 0, Westinghouse Hanford Company, Richland, Washington.

${ }^{3}$ SNF-8346, 2001, Cost-Effective Maintenance Structure for the Spent Nuclear Fuel Cleanup Program, Rev. 0, Fluor Hanford Company, Richland, Washington.

${ }^{4}$ SNF-9290, 2001, Prioritization of Spare Parts for the Spent Nuclear Fuel Cleanup Program, Rev. 0, Fluor Hanford Company, Richland, Washington. 


\section{SNF Predictive Maintenance Project}

SNF engineering and management staff performed a reliability and maintainability (RAM) assessment of SNF equipment at K-Basins, Cold Vacuum Drying Facility (CVD) and Canister Storage Building (CSB) to identify critical pieces of equipment that appear to be exhibiting a problem failure history. The survey quantified the number of failures, the impact of the failure, the likelihood of future failures, and the consequences of a failure for 89 critical pieces of equipment. Evaluating this data using a weighted riskconsequence approach, the equipment inventory was prioritized based on its potential threat to the mission.

As a natural extension to the RAM process, and utilizing the information from the SNF Preventive Maintenance (PM) Project and SNF Spare Parts Prioritization Project performed by PNNL, an effort was commissioned to evaluate opportunities for deployment of predictive maintenance techniques on high-risk equipment. The object of this task is to minimize operational risk in a cost effective manner.

PNNL provided O\&M technical experts to perform an on-site characterization of potential critical equipment applications of predictive O\&M improvements at SNF facilities. The principal focus areas during the on-site characterization were to work with SNF engineers and management to accomplish the following:

- $\quad$ Using the PM and Spare Parts risk based prioritization data and reliability assessment results, select items with the highest O\&M benefit potential for predictive maintenance implementation success.

- Gather the information necessary to fully understand the mode-mechanismstressor relationships leading to equipment reliability problems.

- Based on this information, recommend the optimum O\&M strategy for the equipment.

- If a predictive approach is determined to be desirable then compare the cost of predictive maintenance implementation against the current O\&M strategy.

This report is being prepared as a portion of the project deliverable, and summarizes the areas evaluated, the data gathered, and cost-based recommendations for improvement.

\section{PREDICTIVE MAINTENANCE EVALUATION METHODOLOGY}

During the past 10 years, PNNL has developed the Decision Support for Operations and Maintenance (DSOM) program. This holistic approach to reducing O\&M costs is founded in Root Cause Analysis (RCA) and Condition Based Maintenance (CBM), and engages the entire support infrastructure necessary to optimize and maintain a high level of O\&M effectiveness. The application of the principles of this program to the K-Basin O\&M elements is resulting in an increase of safety and reliability while simultaneously reducing cost. 
The DSOM approach utilizes an event and causal factor methodology to determine root cause. It combines this method with a unique extension of the condition based maintenance approach to identify the underlying stressor(s) that activate specific degradation mechanism(s) that lead to the identified mode of failure. Once the causal stressor is identified, instrumentation or analytical constructs can be applied to quantify the stressor intensity associated with the operational environment of the failed component. The goal is to establish operational constraints that can limit stressor values to levels that will preserve the equipment functionality until completion of the project. For example, the specific case of the failed K-Basin primary cleaning machine pump (P2) the proposed solution would be to:

- Secure relevant failure mode information. This would include design information from the manufacturer, visual inspection of the failed pump, creation of a time line scenario, relevant operational parameters leading to the failure, and observation of the O\&M crews.

- Identify degradation mechanisms that could conceivably be responsible for the failure considering the time line, operational history, and equipment environment.

- Based on the identified mechanisms, develop a stressor set that would activate these mechanisms. For example, pump erosion may be due to cavitation (suction temperature/pressure), particulate in the flow stream, or operation outside the design envelope (throttled suction or discharge).

- Decide on alternatives to measure stressor elements or measure the resulting degradation mechanism(s). For example, the primary cleaning machine pump has an associated flow and pump motor current already recorded in the IWTS data logger. Trending of these parameters or analytical derivatives may, when displayed to the system operators, provide insights into preservation of equipment.

This report summarizes this and other such processes for the critical equipment listed in the reliability and maintainability (RAM) assessment of SNF equipment at K-Basins, Cold Vacuum Drying Facility (CVD) and Canister Storage Building (CSB).

\section{K-WEST INTEGRATED WATER TREATMENT SYSTEM}

The K-West Integrated Water Treatment System (IWTS) is designed to purify water coming from the Fuel Retrieval System (FRS) or directly from K-West basin. The system draws water from three different sources in the K-West basin using three pumps (P1, P2, and P3) in a parallel arrangement. These pumps move water and entrained particulate (which is pre-filtered to remove particulate larger than $1 / 4$ in) through a knockout pot which is designed to filter out particulate down to 200 microns. Additional particulate is removed in a bank of 10 settlers (low flow velocity settling pipes) and then a booster pump moves the water through a bank of 3 sand filters. Finally, an ion exchange bank treats the water before returning it to the K-West basin. 
The IWTS pumps were determined to be high-risk equipment for the following reasons:

- An engineering assessment of the IWTS shows that all three of these pumps must be running to retrieve fuel, and there is no redundancy such that a single failure of any one pump stops fuel retrieval operations.

- The PNNL spare parts prioritization effort identified these pumps as critical to production, operating in an adverse environment, having a high failure probability, with no installed backup capability.

- The SNF availability assessment identified these pumps as having failed in the past, having a high potential of future failure, and are associated with a high down time and installation costs.

\section{A. IWTS System Analysis}

Based on the information above, the IWTS pumps were selected for a detailed assessment. The following issues were identified during this assessment:

\section{The design of these pumps makes them susceptible to failure for their current application.}

The IWTS P1, P2, and P3 pumps are centrifugal pumps running at $3500 \mathrm{rpm}$. The pump and motor are connected directly by a shaft with a lower and upper seal. The cavity between the pump and motor is filled with oil. A simplified diagram is shown in Figure 1 below.

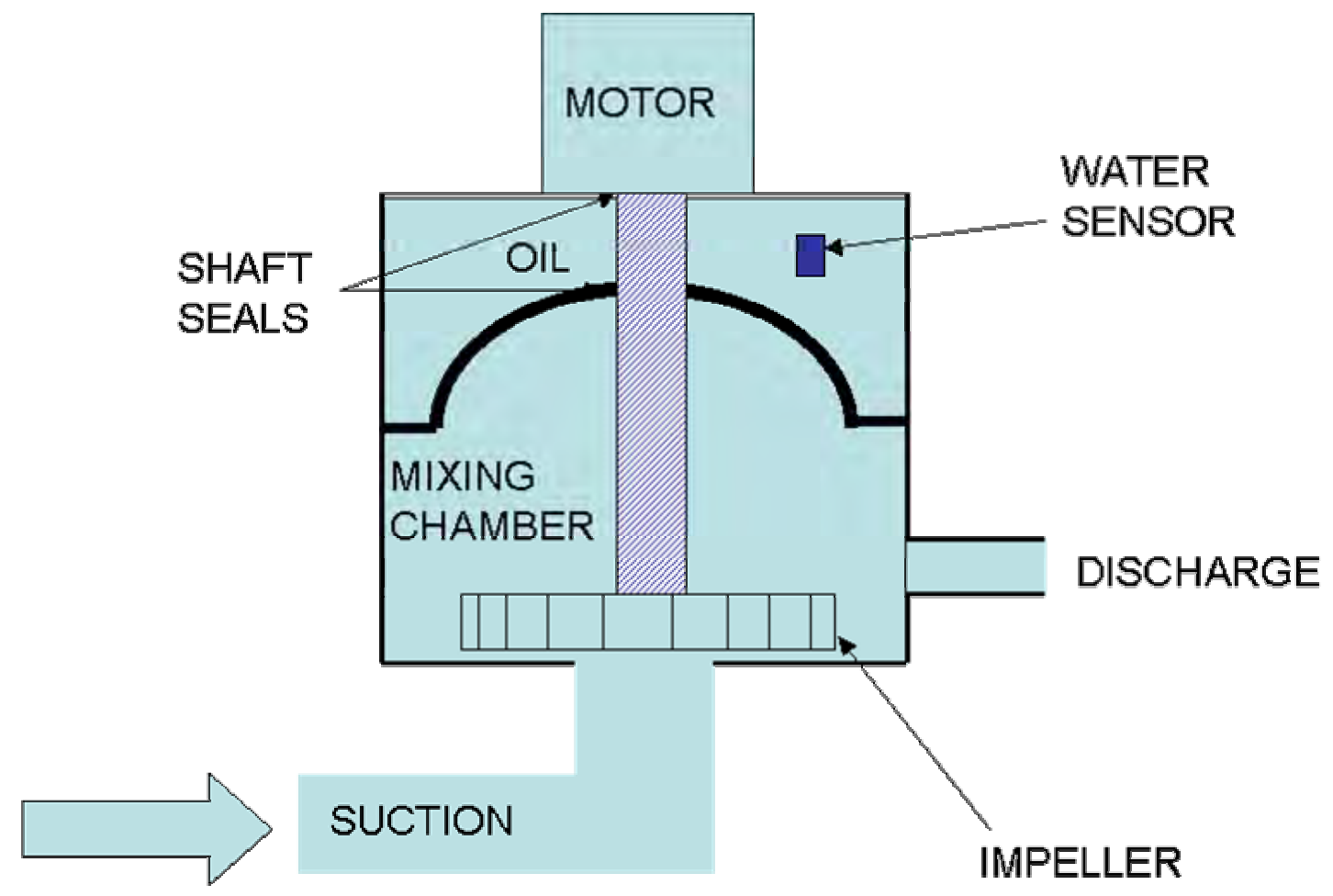

Figure 1. IWTS Pump (P1, P2, and P3) Design Schematic 
A portion of the lower seal is exposed to the water/particulate environment. The pump cavity is relatively large that likely results in large secondary flow patterns within it. With the entrained particulate, this could be causing an erosion problem resulting in failure of the lower seal and upper pump casing.

Initially, the pump was fabricated from 316 stainless steel. The material was changed to 2507 stainless steel to correct erosion problems that occurred during testing. The

new material was never re-tested. Additionally, the member between the pump cavity and oil cavity is made of cast iron. This member may be experiencing excessive erosion. This could be leading to water contamination in the oil cavity and degradation of the lower and/or upper seal.

\section{The diagnostic and monitoring equipment associated with the IWTS pumps are very limited.}

Currently, over thirty-five parameters are compiled, with the data logged onto a hard disk utilizing Wonderware software, and periodically archived onto a CD. The data includes the following parameters for the three IWTS pumps:

- P1 (decapper) Pump Current (CT-206-1)

- P2 (primary cleaning machine) Pump Current (CT-206-2)

- P3 (downdraft) Pump Current (CT-206-3)

- P1 (decapper) Pump Flow (FIT-206-05)

- P2 (primary cleaning machine) Pump Flow (FIT-206-06)

In addition to the limited monitoring performed, the pump current monitoring is based on an inductive system that is only capable of detecting longer duration changes in pump current. It lacks the frequency response necessary to detect short duration transient events needed to perform a more complete motor current analysis.

\section{Current operating practices may be contributing to IWTS pump failure.}

The 3 IWTS pumps have a common discharge header that does not contain check valves. The original intent was for all 3 IWTS pumps to be started simultaneously. Therefore, backflow through the pumps was not thought to be a concern, and consequently, check valves were not installed on the discharges of the pumps. It was later discovered that the IWTS pumps maximum discharge pressure during a 3 pump start is 129 psig and this was causing failures of the downstream rupture disks set at 125 psig. To correct these failures, the starting procedure was modified to start each pump individually in order to minimize the starting transient. This results in significant backflow through the $2^{\text {nd }}$ and $3^{\text {rd }}$ pumps and may cause one or both of them to rotate backwards. The vendor (Corcoran) specifically warns against rotating these pumps backward as it will result in reducing the life of the pump (stress on pump seals) and motor (could produce an excessively high starting current). 
In an effort to determine if these conditions were actually occurring, archived data was acquired and plotted. Figure 2 shows the flow and pump current data for the P1, $\mathrm{P} 2$, and $\mathrm{P} 3$ pumps during a typical starting transient.

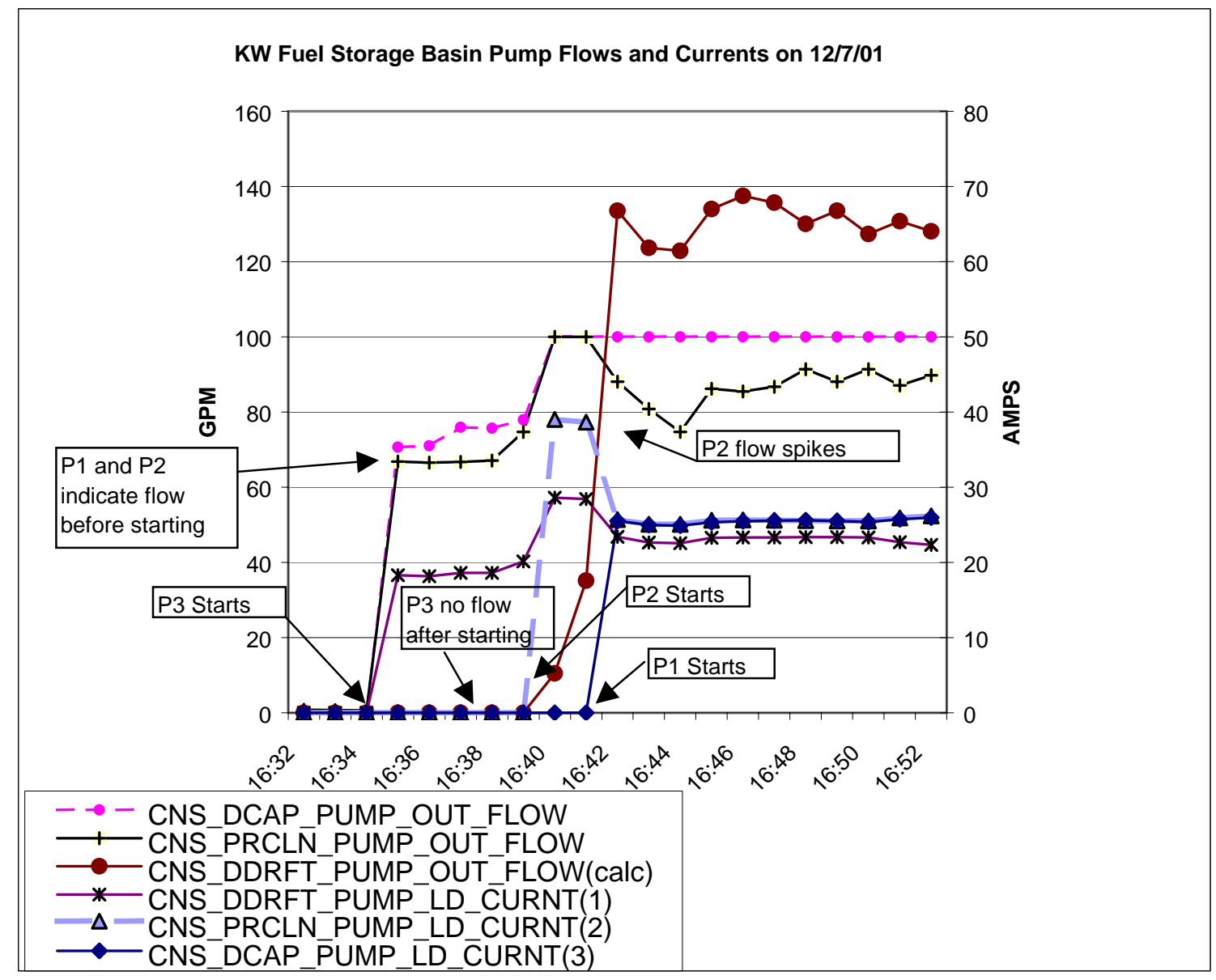

Figure 2. Starting Transient for IWTS Pumps P1, P2, and P3

As noted, these pumps discharge into a common header without check valves and are sequentially started in the following order:

- P3: Canister Downdraft Pump (water from the Process Table)

- P2: Canister Primary Cleaning Pump (water from Primary Cleaning Machine)

- P1: Canister Decapping Pump (water from Canister Decapping)

Several start-up sequences were studied and determined to be similar in behavior characteristics (see Appendix A). Two issues that can be seen from the graph:

- At time 16:35, P3 starts up, and immediately flow is detected by the flow meters at the discharge of P2 and P1 which indicates significant back flow into these pumps (the flow sensors register flow in either direction). Although P3 is on, no flow is indicated since the flow for P3 is calculated by subtracting the total flow 
reading from a downstream flow sensor (at the Canister Booster Pump) from the combined flow of P1 and P2.

- At time 16:40, the second pump (P2) starts and the current spikes up to a maximum of 39 amps. At 16:40, the $\mathrm{P} 3$ reaches $100 \mathrm{gpm}$, the maximum range on the meter and remains at that level (pegged indication) until shut down. The same can be seen in other sequences for $\mathrm{P} 2$.

\section{The Wonderware software is not configured to provide useful trend data to the Cognizant Engineer.}

Currently, the data that is electronically logged goes into a data file on a computer that is not connected to the network and so is not remotely accessible by the Cognizant Engineer. Additionally, the data is stored in a format that requires significant manipulation by the Cognizant Engineer in order to obtain good trend information. This has resulted in the Cognizant Engineer not utilizing the data on a regular basis as a tool to predict failures. In fact, several months of data were lost when the data acquisition system failed. The data was not being used and so no one noticed the failure.

\section{B. IWTS System Recommendations}

Based on the analysis above, the following recommendations are made:

\section{Consider making system design changes.}

Implementation of a Variable Speed Drive (VSD) on the IWTS pumps could potentially correct or partially correct at least two of the design problems:

- A VSD should eliminate the backflow problem through the pumps during the starting sequence. It should be possible to start all three pumps simultaneously without failure of the rupture disk if they were initially started at a reduced speed. After the starting transient had subsided, the pump speeds could then be slowly increased to operating speed.

- A VSD would potentially allow the pumps to be operated at a lower speed. The pumps are currently operated at $3500 \mathrm{rpm}$ that could be causing erosion problems with the seals and cast iron internal structure due to secondary flow patterns inside the pump. The secondary flow and resulting erosion might be reduced by lowering the normal operating speed of the pumps.

Installation of check valves on the discharge of these pumps as recommended by the manufacturer would also solve the backflow problem. This would not improve the erosion problem. A potential solution for the erosion problem would be to fabricate the upper pump casing out of a more erosion resistant material.

\section{Consider installing additional diagnostic and/or prognostic monitoring equipment on the pumps.}


Installation of additional diagnostic and/or prognostic monitoring equipment could be used to help monitor the IWTS pumps. This information could then be processed and used to help predict an impending failure of the pump. Monitoring equipment might be installed that would help detect stressors on the pumps and give operators or engineers early enough warning to correct the stressor before damage is done to the pump or plan just in time maintenance on the pump. This would have the affect of increasing the life of the pump or reducing the down time. Monitoring equipment could also help identify the failure mechanism of these pumps. For example, by obtaining sensor data that gives us a better understanding of the affects of particulate as it goes through the IWTS pumps during a fuel washing cycle would help determine the failure mechanism and how to avoid this mechanism.

Before a solid recommendation can be made, the failure mode of the pump must be determined. An inspection is planned on the failed pump, but has not yet occurred. Based on the results of this inspection, additional recommended monitoring might include:

- $\quad$ Acoustic Emission Monitoring - This sensor (essentially a small microphone) would be placed on the pump to transmit an acoustic signature for the pump. This highly effective sensor can be "tuned" to identify general precursory degradation events such as pump cavitation and specific events such as ingestion of fuel fragments. Event identification algorithms for acoustic sensors are currently being developed and tested in the Laboratory and could be ready for implementation by as early as April, 2002.

- Vibration Monitoring - This is the standard for machine health monitoring and could be configured to provide automated alarms through the proposed DSOM IWTS system. It would be necessary to install the sensor on the pump housing. While alarms would be automated, interpretation of event data would require expert analysis from the Laboratory.

- Transient Detection of Pump Motor Current - In addition to performing trending and alarm functions of motor current, which would be accomplished by the proposed DSOM IWTS system, interpretation algorithms could be brought to bear for detecting specific abnormal motor behavior. This sensor would be nonintrusive in that it would be installed at the motor control center rather than having to be placed on the pump itself.

\section{Consider implementing a software application that will provide a more useful trending interface for the Cognizant Engineer.}

An examination of the data utilization effectiveness showed several opportunities for improving the trending, analysis, and timely display of IWTS data. Under the current scheme, the data recorded by the IWTS data logger is to be reviewed and transferred to a compact disc (CD) medium for permanent storage and retrieval. This information prior to the P2 pump failure would have been extremely valuable in determining the failure mechanism of the pump. Unfortunately, there was a problem with the CD transfer mechanism for this data and it had not been preserved for a period of six months prior to and three months after the pump failure. This brings up three potential improvements: 
- Data recording, storage and retrieval

- Timely data analysis

- Timely data display

One solution to these opportunities is to put in place an automated system that preserves the data for easy recall, provides expert analysis and auto-trending of the data set, and provides real-time display of system parameters and automated diagnostics. This objective could be achieved by a limited implementation of a Decision Support for Operations and Maintenance ${ }^{\circledR}$ or DSOM system for the ITWS.

As part of this task, a set of prototype screens were developed for demonstration purposes. This mini-DSOM system would provide the following functionality for the ITWS:

- When coupled with the ITWS data logger, it would provide complete backup for the data logging system. This includes all data acquisition and recording functions.

- The DSOM ITWS would provide a level of expert system data analysis that would include:

a) Normal, alert, and alarm band status annunciation for all primary (direct) and virtual (calculated) parameters. Alerts would provide a prognostic function to determine remaining time before an actual alarm level (design limit) is reached (see Figure 3).

b) DSOM diagnostics would be provided for alarm conditions that would be considered likely by the engineering and operations staff.

Diagnostics, when triggered, would give operators a root cause process outline and recommended corrective actions.

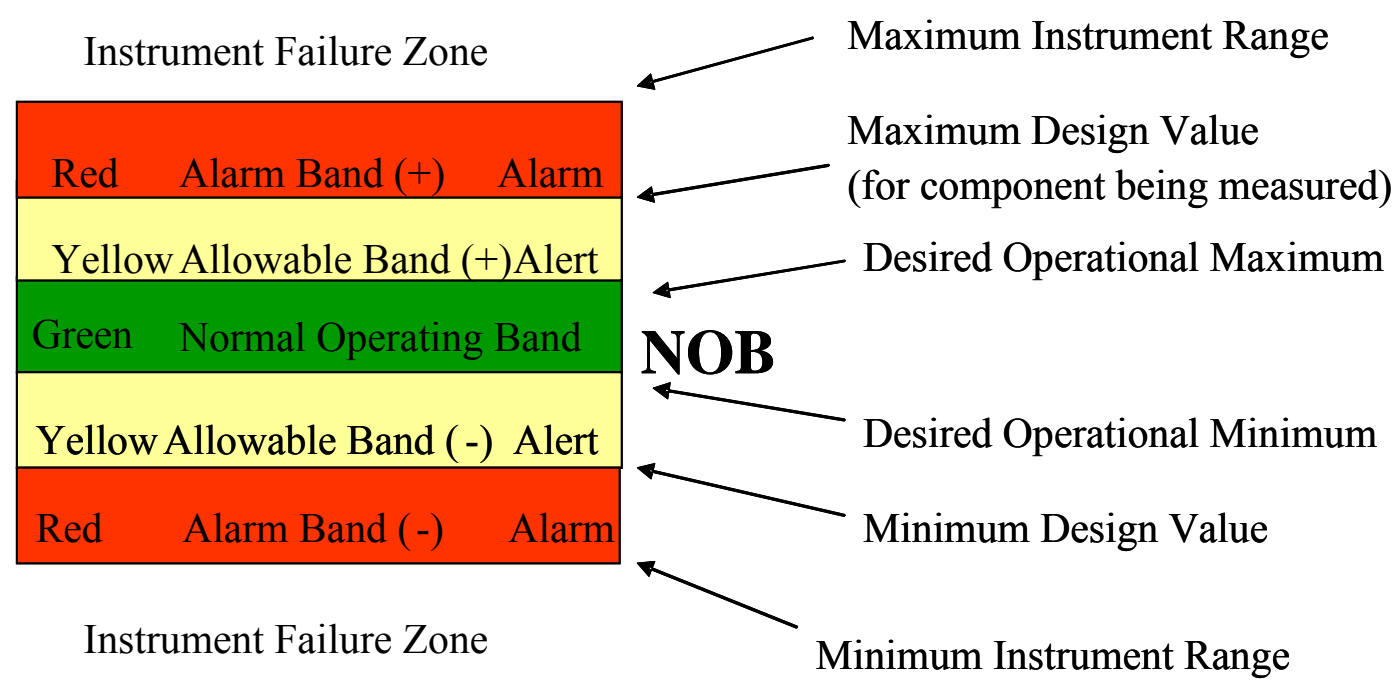

Figure 3. Operating Band Concept 
- Data display would be provided to the system operators in the form of a hierarchical computer schematic (see Figure 4). The top level screen displays overall system status.

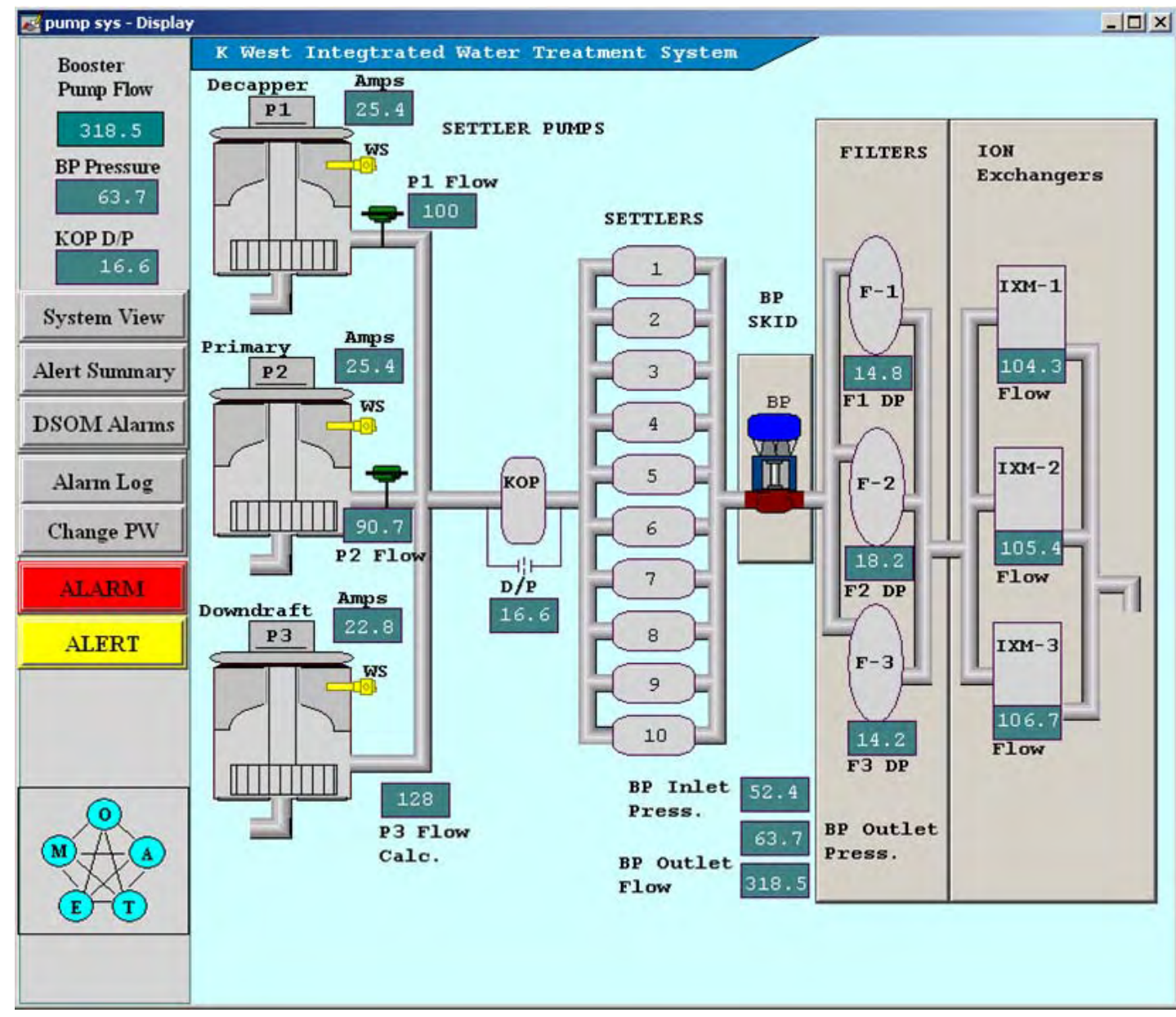

Figure 4. ITWS System Level Schematic

The schematic portion of the screen provides a level of oversight required for normal system operation, including the status of operational components and associated parametrics. The column on the left is shown with all DSOM screens and provides critical system parameters, alarm functions and administrative functions. Alarm summaries and logs provide indication of when alarms were received, acknowledged, and cleared. An alarm condition in a given area "blinks" until acknowledged and remains "lit" until the condition is cleared. Any parameter shown on a DSOM screen can be plotted in a graphical format by simply clicking on it with the cursor. This provides a historical plot of the parameter using variable time windows.

The schematic is broken down into four major stations as configured in Figure 4: pumps with associated knock out pot and settling volumes, a booster pump skid, filter vessels, and ion exchange modules. By clicking on a station level "button" the display shifts to that area detail and provides additional instrumentation on that area. Figure 5 shows the booster pump skid view. 


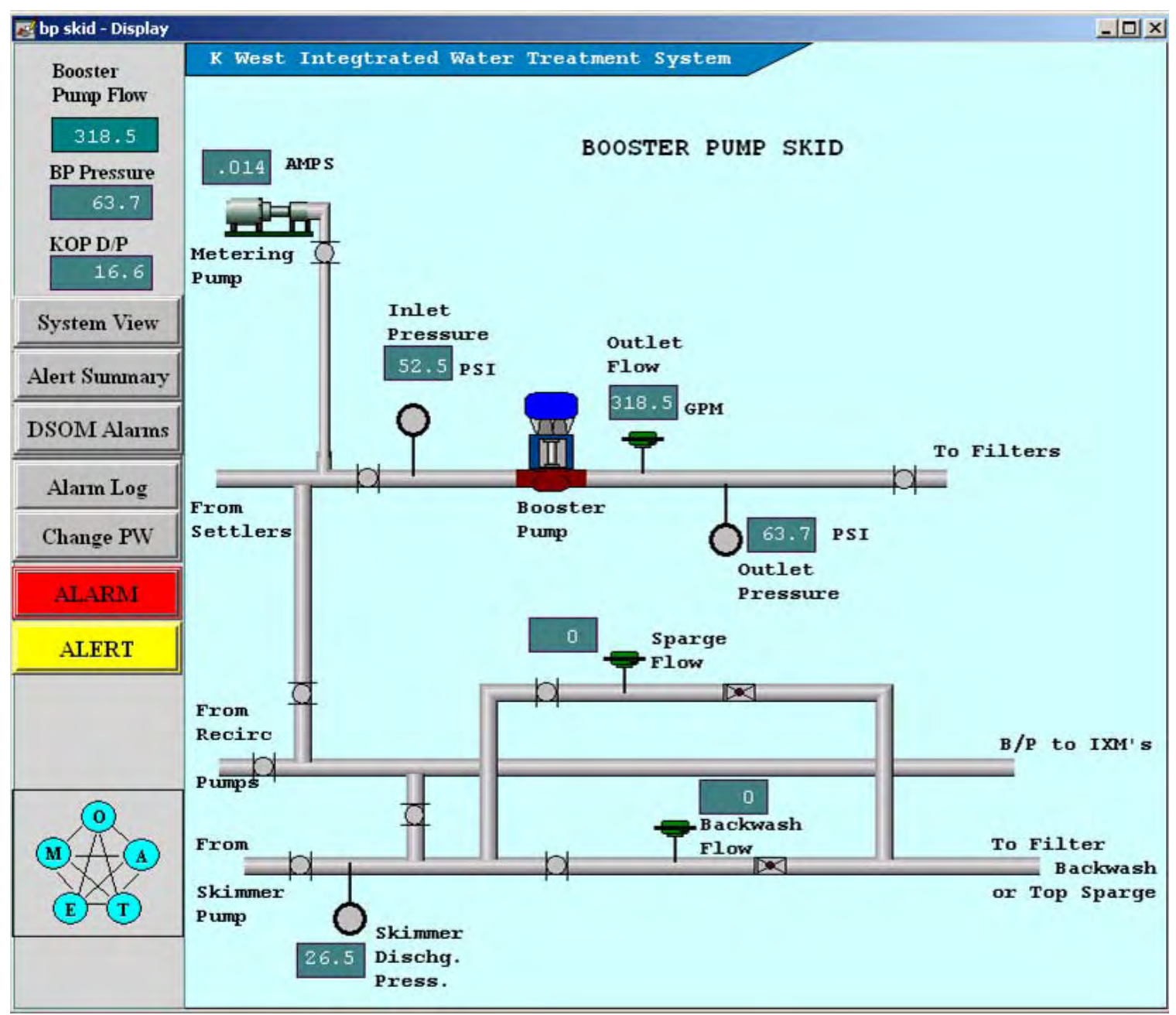

Figure 5. Booster Pump Station

In this view, details not visible in the system level view are displayed such as the metering pump. Alarmed variables are highlighted and, as in all screens, plots can be viewed by a single click on the parameter of interest. Similar detail can be seen in Figures 6 and 7 for the filter bank and ion exchangers. To return to the system schematic level the System View button is clicked. 


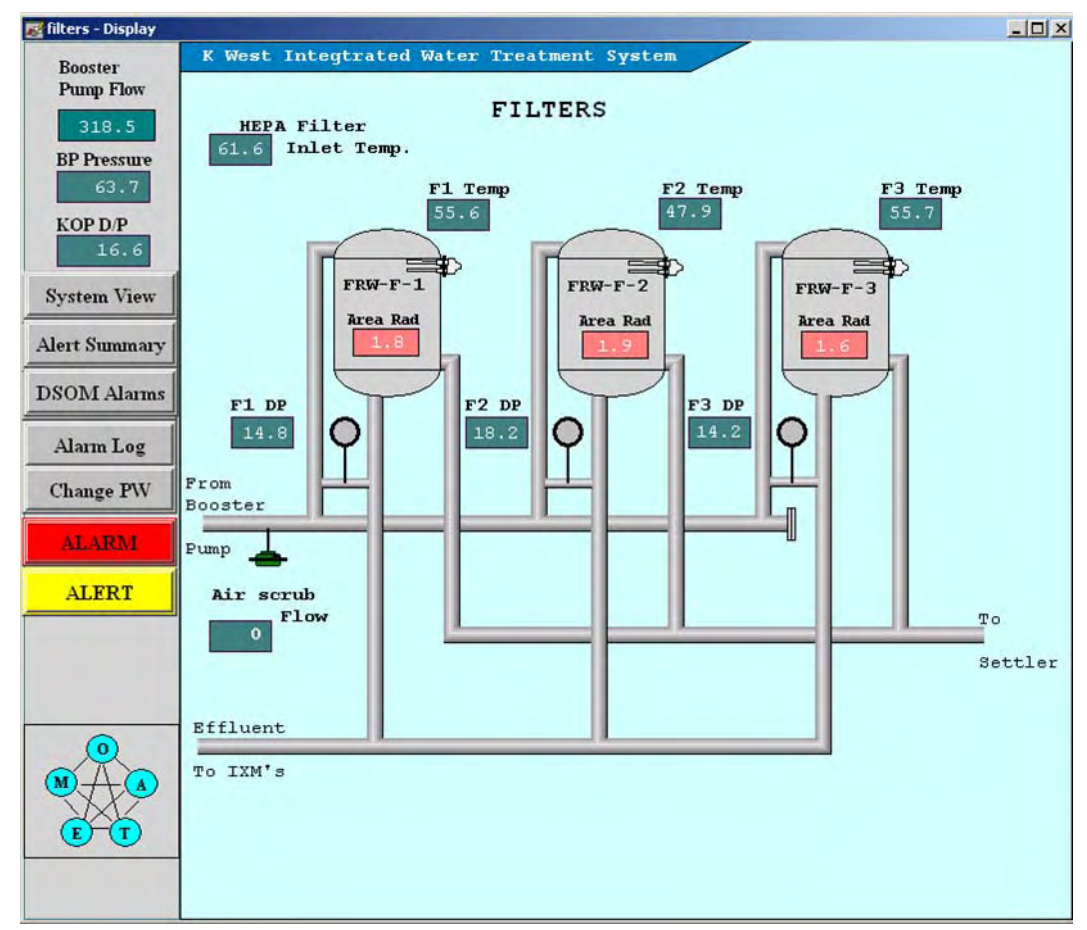

Figure 6. Filter Bank Station Display

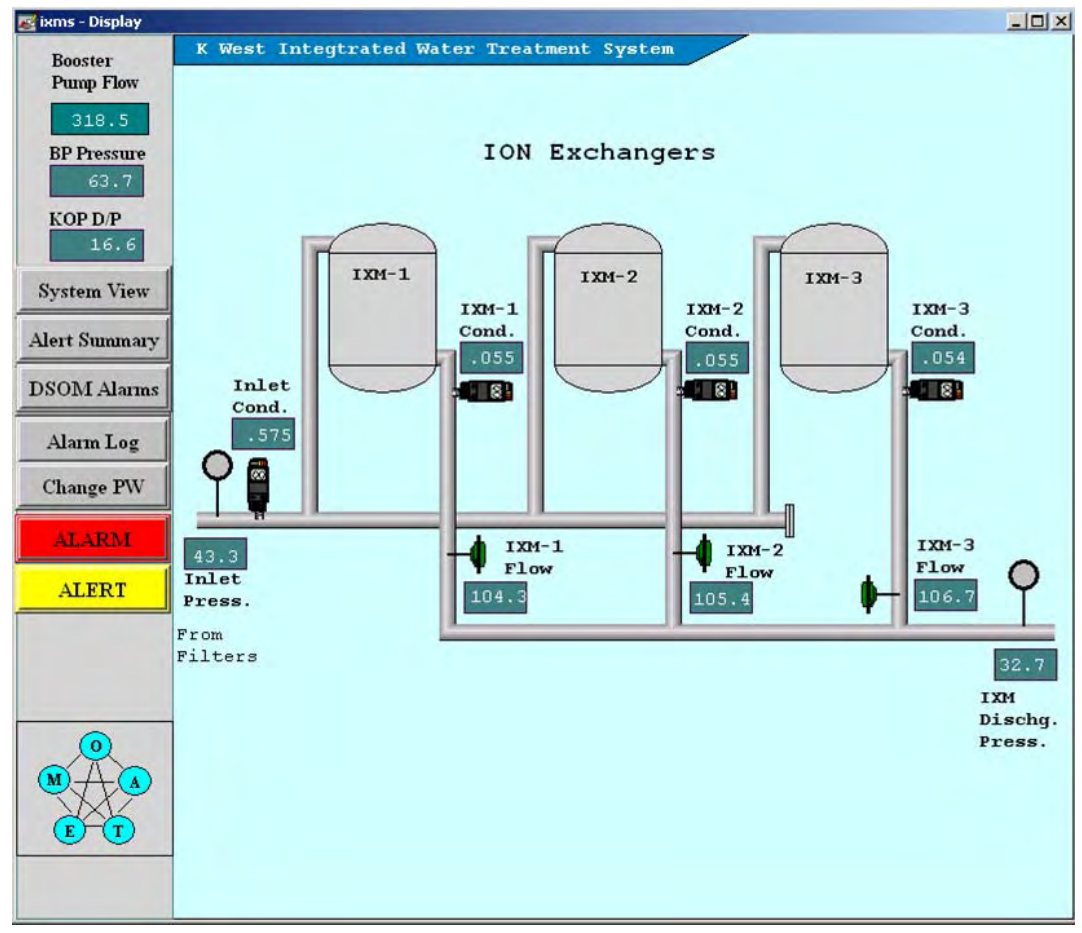

Figure 7. Ion Exchange Bank Display

Due to the intuitive layout and limited scope of this system, training time is expected to be minimal for the operators and engineers. This system is expected to improve the operation and maintenance of the IWTS by providing visibility to real-time information, 
operational limits, and diagnostic alarms for the operating crew and allow easy trending of data for the engineer.

\section{CVD VACUUM PUMPS}

The CVD has four vacuum pumps in the facility, three associated with fuel drying and one associated with the residual gas analyzer. Only the three associated with MCO drying were investigated. These pumps contain five stages and run at $3600 \mathrm{rpm}$. Discharge shaft seals are purged with helium. Instrumentation includes suction pressure, inert gas purge flow rate, and cooling water temperature.

The CVD vacuum pumps were determined to be high-risk equipment, and were selected for a detailed review for the following reasons:

- The SNF availability assessment identified two failures of vacuum pumps in the past.

- The PNNL spare parts prioritization effort identified these pumps as critical production, having failed in the past, with no installed backup capability.

- An engineering assessment of the CVD vacuum pumps identified that failure of a vacuum pump can affect MCO processing.

\section{A. CVD Vacuum Pump Analysis}

The first failure of a vacuum pump was probably caused by poor operations. When the vacuum pump was first started, a plug was left in the discharge and the suction was open. This resulted in a current overload condition and the breaker tripped within seconds. The breaker was damaged and required replacement. The pump was also likely damaged. Additionally, during early operation of the vacuum pumps, they were frequently started and stopped. Due to very tight internal tolerances, the vendor recommends that a onehour temperature equalization period is provided before restarting these pumps.

The second failure occurred within 2 days of installation of the pump and this failure is attributed to infant mortality. Since these failures, approximately $45 \mathrm{MCO}$ 's have been processed with no additional failures reported.

CVD Engineering is currently collecting and trending vacuum pump suction pressure data. This is very helpful in detecting degradation in pump performance. The best indicator of pump performance is obtained before an MCO is connected. The pump is run with the suction valve shut and the suction pressure is recorded. The data associated with the current pump shows no degradation trends thus far. Samples of this trend data are shown in Appendix B.

Even though the vacuum pumps seem to be operating well at this time, the consequences of a failure are significant. The cost of a new pump is approximately $\$ 25,000$.

Additionally, replacement of a failed pump is complicated by the requirement to treat it as potentially internally contaminated and the need for multiple crafts to perform the 
change out. Failure of the pump stops processing of the on-line MCO and could require days to repair and restart. Therefore, due to the severity of the consequences of failure, it is recommended that additional monitoring and trending be performed on these pumps. Monitoring of motor amps is difficult because both suction pressure and temperature significantly affect the reading and must be compensated for in order to obtain meaningful trending information. Vibration monitoring is not significantly affected by other parameters and so is the recommended mechanism for additional monitoring.

\section{B. CVD Vacuum Pump Recommendation}

\section{Consider installing additional diagnostic and/or prognostic vibration monitoring equipment on the pumps.}

Monitoring equipment could be installed that would detect when stress is being applied to the pumps and give operators or engineers early enough warning to correct the stressor before damage is done to the pump. This would have the affect of increasing the life of the pump. Installation of additional vibration monitoring equipment would also help predict an impending failure of the pump. This would give engineers and maintenance more time to plan an outage.

Vibration monitoring equipment is standard for machine health monitoring and could be configured to provide automated alarms. It would be necessary to install a piezoelectric vibration sensor on the pump housing. While alarms would be automated, interpretation of event data would require expert analysis from the Laboratory.

\section{CVD SUPPLY, EXHAUST, AND RECIRCULATION FANS}

The CVD HVAC system includes a general supply fan, a general exhaust fan, two local exhaust fans (safety significant), and four bay recirculation fans. Fans are driven by motors with either two or three fan belts.

A number of problems with CVD fans were identified in the SNF availability assessment, however, most of them have been corrected. The CVD fan belts were determined to be medium-risk equipment for the following reasons:

- The SNF availability assessment identified these fan belts as having failed frequently in the past.

- An engineering assessment of the CVD fans identified that failure of a local exhaust fan or recirculation fan stops MCO processing or prevents an MCO from being received. Additionally, problems with failing fan belts have continued.

\section{A. CVD Supply, Exhaust, and Recirculation Fans Analysis}

Fan belt mean time between failure has been determined to be at approximately five to six months. Therefore, the preventive maintenance activity for the fan belts has been increased from biannually to quarterly. The maintenance activity consists of a visual 
inspection by the craftsman for vibration, noise and fan belt wear. The maintenance activity takes approximately six hours to complete. When a fan belt fails, it can be replaced within about four to six hours.

Vibration monitoring on the fan shafts could be used to detect degradation of the fan belts and provide operators an early warning to replace the belts before they failed. This would allow the preventive maintenance periodicity to be extended significantly. However, the cost to the preventive maintenance is small. Additionally, if a fan belt does fail, the consequences are only moderate because the belt can be rapidly replaced. Therefore, it is determined that predictive maintenance techniques would not be cost effective in this case.

\section{B. CVD Supply, Exhaust, and Recirculation Fans Recommendations}

None.

\section{CVD UNINTERRUPTIBLE POWER SUPPLY}

The CVD Uninterruptible Power Supply (UPS) provides regulated, clean, continuous power for systems critical to safety, and continuous power during and after a design basis accident. Uninterruptible power from the UPS-1 is provided in the case of site normal power outages. It is located at the CVD in room 129. The UPS drawing is H-1-82246.

PNNL was requested by CVD engineering to evaluate and recommend diagnostic techniques for the UPS based on the following criteria:

- Allow for a quick connection to the system

- Provide early warning of potential problems

- Allow for testing and troubleshooting if a problem is indicated

- Provide ease of implementation

\section{A. Analysis of the CVD UPS System}

It was determined that the Canister Storage Building (CSB) has an identical UPS system as CVD. After discussion with CSB engineering, it was also discovered that there is currently a Solidstate Controls, Inc, 3SE Series monitoring system in place for the UPS. This system has the following monitoring capabilities:

- DC Output Voltmeter - monitors the DC output voltage of the charger and the DC bus in the UPS.

- DC Output Ammeter - monitors the DC output current of the charger.

- Inverter Output Voltmeter - monitors the AC output voltage (A-B, B-C, and C-A) of the inverter using a selector switch.

- Inverter Output Frequency Meter - monitors the frequency at the output of the inverter.

- AC Output Ammeter - monitors the AC output current of the Charger. 
- Battery Breaker Open Alarm - senses when the battery input breaker is open. A SPDT alarm contact and a red pilot light are supplied as standard for annunciation. The alarm relay is energized under normal conditions.

- Low DC Voltage Alarm - senses when the DC bus voltage drops below 120 VCD. A SPDT alarm contact and a red pilot light are supplied as standard for annunciation. The alarm relay is energized under normal conditions. This could provide an indication of a problem associated with connections, individual battery performance or other more intrusive determination requirements.

- Static Switch Transfer Alarm - senses when the Static Switch has transferred from normal operation to Bypass Source supplying load. A SPDT alarm contact is supplied as standard for annunciation. The alarm relay is energized under normal conditions.

- High DC Voltage Alarm - senses when the DC bus voltage goes above 144 VDC. A SPDT alarm contact and a red pilot light are supplied as standard for customer annunciation. The alarm relay is de-energized under normal conditions. This could provide an indication of a problem associated with connections, individual battery performance or other more intrusive determination requirements.

- Low AC Output Alarm - senses when any phase of the AC output voltage drops below $10 \%$ of nominal. A SPDT alarm contact and a red pilot light are supplied as standard for annunciation. The alarm relay is energized under normal conditions. This could provide an indication of a problem associated with connections, individual battery performance or other more intrusive determination requirements.

- UPS Trouble Alarm - senses all of the other alarms and is activated when any other alarm occurs. A SPDT alarm contact and a red pilot light are supplied as standard for annunciation. The alarm relay is energized under normal condition.

- Out of Sync Alarm - senses when the internal oscillator of the inverter source signal is not in synchronization with the bypass source signal. A SPDT alarm contact and a red pilot light are supplied as standard for annunciation. The alarm relay is energized under normal conditions.

- Inverter Failure Alarm - senses when the inverter is disconnected or not functioning. A SPDT alarm contact and a red pilot light are supplied as standard for annunciation. The alarm relay is energized under normal conditions.

Additional information regarding the above alarm conditions can be found in the Solidstate Controls, Inc. operations manual. The manual contains detailed information plus a recommendation to contact the factory for assistance on any situation outside of the available diagnostics as needed.

The existing system does not have the capability to monitor individual cells. Trending can help determine a cell failure before it actually occurs. The existing system has the capability to relay information remotely if needed.

The CSB UPS system utilizes three procedures that should meet the needs of CVD for operation of the monitoring system. These include a maintenance procedure, loss 
of power recovery procedure, and a general operational guide. The CSB maintenance procedure (MP-20-001V) includes both quarterly and annual inspections.

\section{B. CVD UPS Recommendations}

Based on the analysis above, the following recommendations are provided:

\section{Consider periodic surveillance on the UPS to support optimum system reliability.}

Consider taking periodic readings of UPS system parameters to provide early detection of faults or problems. If a failure history develops, then this data will be available for compiling, plotting and trending. Once targeted parameters are analyzed through trending, additional predictive maintenance could be incorporated.

More advanced methods of system evaluation are available, but given that the current monitoring system obtains all needed information, the added cost of new instrumentation, training maintenance personnel, and development of supporting procedures would not be cost effective.

\section{Consider implementing a PM program on the UPS system.}

The current CSB procedure, MP-20-001V, provides a good starting point for UPS maintenance checks. Consider expanding this procedure with respect to diagnostics as discussed in the Solidstate Controls, Inc. Operations Manual. Incorporation of some of this information into the procedure may be beneficial.

\section{CVD HVAC GENERAL EXHAUST VARIABLE FREQUENCY DRIVE}

Each general exhaust fan if fitted with at Variable Frequency Drive (VFD). These VFD's were selected for analysis because the SNF availability assessment identified 2 failures in the past. Summaries of the failures are as follows:

In the July-August, 2001 time frame, a muffin fan failed allowing the over heating of the electronics associated with one of the VFD units (HVAC-FAN-8025). The muffin fan was replaced and no further actions were taken.

On August 28, 2001 at 19:30 hours while the CVDF was processing a MCO, the General Exhaust flow began to fluctuate, and from 19:35 to 19:37, the flow ramped down to 7\% below normal. At this point, the control system detected a failure of the Lead General Exhaust Fan (HVAC-FAN-8025) and automatically started the Backup General Exhaust Fan (HVAC-FAN-8027). General Exhaust normal flow was reestablished by 19:38. The suspected initiating event occurred at Priest Rapids Dam. The BPA reported a major transformer fire at the dam from which the generators were suddenly shed. At 19:33 (grid time), the Substation transient recorder was triggered by and recorded the under 
voltage condition corresponding to the incident at CVDF. The system was evaluated superficially and determined to be operational, so that the failed exhaust fan was brought back online.

\section{A. Analysis of the CVD Variable Frequency Drive Problem}

Based on discussions with the VFD vendor, it was learned that there are two operating modes (Free-Wheel and Ramp) for the VFD that result in a different response to a loss of power event. The CVD VFDs are utilizing the Ramp mode, and it was determined that the system worked as prescribed by the vendor. The parameters are either set at the factory for application specific requirements, or set at the site of application. In either case they are stored in EPROM for up to 10 years. Another available option for storing parameters is the use of the PCMCIA card (this allows the drive configurations and adjustments to be saved and then downloaded in another drive to be reloaded after system failure). Most VFDs allow partial or total reset of drive settings. Although parameters are stored in an EPROM, determination of which settings may have been impacted by a system failure would assist in future observations

Additionally, it was learned that when a VFD unit fails, the fault code is displayed on the controller display. These codes include but are not limited to the following: short circuit between phases, short circuit to ground, internal fault, transistor in short circuit, or transistor open, etc. The diagnostic menu can be located on menu 8 of the controller. This will allow more in-depth determination of possible problems such as but not limited to the following: $\mathrm{I} / \mathrm{O}$, memory, transistor performance, testing of the inputs and outputs with forcing of the outputs, etc.

According to records, within two minutes of temporary loss of power the backup exhaust fan was initiated. One minute later the system was at full operation. The current spike had tripped the breaker of the online fan. The system seemingly worked well in response to a loss of power. Loss of the muffin fan caused over heating of the systems' electrical boards and may have made this unit more sensitive to outside influences.

The engineer for the VFDs stated that the harmonics associated with the VFD units are suspect to have interference qualities concerning other more sensitive systems, for example the Uninterruptible Power Supply (UPS) system. Discussions have taken place to investigate the source of these harmonics and/or evaluate UPS system with respect to specific monitoring criteria.

\section{B. CVD Variable Frequency Drive Recommendations}

Based on the analysis above, the following recommendations are made:

\section{Extract error codes from the VFD controller queue.}

Based on information from the VFD system engineer, evaluation of specific controller error codes hasn't occurred. Extracting the error codes to help confirm the analysis above and to clear existing codes so future failures are logged and can be extracted during troubleshooting efforts. 


\section{Validate VFD control parameters are set as desired.}

Based on information from the VFD system engineer, determination of control parameter settings following the previous failures has not occurred. Because control parameters could have been reset to default settings by the loss of power, it would be advisable to recheck them to ensure they are set optimally.

\section{Isolate VFD induced harmonics.}

If it is determined that VFD harmonics are causing problems with other sensitive systems, then it is recommended that these systems be protected from the harmonics rather that attempting to eliminate the harmonic. This can be done by utilizing isolation transformers for critical systems such as the UPS system, and/or using isolation devices that can be incorporated into the breaker box or in line with specific units of concern. 